\title{
ОЦЕНКА ЭФФЕКТИВНОСТИ ФУНКЦИОНИРОВАНИЯ БЮДЖЕТНОЙ СИСТЕМЫ НА СОВРЕМЕННОМ ЭТАПЕ РАЗВИТИЯ
}

\author{
(C) 2018 Маремкулова Рузанна Натарбиевна \\ кандидат экономических наук, доцент \\ кафедра конституционного и административного права \\ Институт права, экономики и финансов \\ Кабардино-Балкарский государственный университет им. Х.М. Бербекова \\ 360004, г. Нальчик, ул. Чернышевского 173 \\ E-mail:mnruzanna@mai.ru \\ (c) 2018 Закураев Азамат Мухамедович \\ магистрант \\ Институт права, экономики и финансов \\ Кабардино-Балкарский государственный университет им. Х. М. Бербекова \\ 360004, г. Нальчик, ул. Чернышевского 173 \\ E-mail: bas-07@yandex.ru \\ (C) 2018 Доткулова Залина Олеговна \\ магистрант \\ Институт права, экономики и финансов \\ Кабардино-Балкарский государственный университет им. Х. М. Бербекова \\ 360004, г. Нальчик, ул. Чернышевского 173 \\ E-mail: Zalina-dotkulova@mail.ru \\ (c) 2018 Озрокова Ляна Хасановна \\ магистрант \\ Институт права, экономики и финансов \\ Кабардино-Балкарский государственный университет им. Х.М. Бербекова \\ 360004, г. Нальчик, ул. Чернышевского 173 \\ E-mail: Lyana.ozrokova.ozrokova@mail.ru
}

В статье рассматриваются актуальные проблемы государственного управления бюджетной системой страны, правовые аспекты реализации функций государства на федеральном уровне, применительно к государственно-территориальным образованиям и местному самоуправлению. Важнейшим моментом в этом процессе является эффективность государственного управления в бюджетной сфере в рамках сложившихся институтов в бюджетной сфере, которая реализуется в форме социально-экономического наиболее рационального выбора использования бюджетного ресурсов. В работе показано, что достижение высокой эффективности бюджетного финансирования на всех его уровнях предполагает наличие в рамках институциональных форм этого процесса интеграцию аудита в институты управления бюджетной сферой от федерального до местного уровня.

Ключевые слова: государство, право, институты, управление, бюджет, бюджетная система, бюджетное устройство, эффективность, аудит, финансовая деятельность.

Государственное управление организацией и функционированием бюджетной системы представляет собой определенный институт, который на основе действующего законодательства обеспечивает реализацию функций государства, государственно-территориальных образований и органов местного самоуправления. В экономико-правовом аспекте на всех уровнях хозяйствования в рамках этого института возникает вопрос об эффективности бюджетной системы. Центральное внимание здесь сосредоточено на правовом порядке обеспеченности бюджетными ресурсами, закрепленными в Законах Российской Федерации и её субъектов, а также соответствующими нормативными актами, реализация которых обеспечивает достиже- 
ние социально-экономических целей государственной политики страны. Вопрос об эффективности реализаций функций государственного управления бюджетной сферой ставиться более актуальной в современных условиях развития России. Соотношение социальноэкономического эффекта и соответствующих используемых бюджетных ресурсов в значительной степени определяется уровнем организации бюджетной сферы, эффективностью реализаций государственных функций по её управлению. Реализация социально-экономической политики государства в целом в значительной мере зависит от решения этой проблемы. Правовые нарушения в бюджетной сфере оказывают негативное влияние на социально-экономическую ситуацию в обществе. Недостаточное финансирование снижает эффективность всего государственного управления бюджетной сферой, следовательно, и всего государственного управления. Однако и при достаточном финансировании этой сферы низкий уровень её организации и управления также становиться фактором, направленным против реализации социально-экономической политики нашего государства. Поэтому правовая обеспеченность и соблюдение законодательных требований в рамках всего бюджетного процесса становиться обязательным условием эффективности организации и управления бюджетной системы, совершенствования форм и методов её государственного регулирования. Научные исследования в экономико-правовом аспекте являются весьма актуальными в ходе создания и совершенствования современного правового государства. На основании индекса GRICS (Governance Research Indicator Country Snapshot) Всемирного банка, построенного на оценке эффективности государственного управления в 209 странах, Россия по ряду показателей (эффективность работы правительства, качество законодательства, верховенство закона и контроль за коррупцией) находится в нижней части рейтинга [1]. Эти выводы во многом подтверждаются оценками российских экспертов, согласно которым сфера государственного управления в России превратилась в ограничивающий фактор для социально-экономического развития страны и повышения ее мировой конкурентоспособности [2]. В сущности данная проблема решалась в ходе административной реформы в России, в рамках которой повышение эффективности де- ятельности органов исполнительной власти имело важнейшее значение. Вообще эффективность является весьма исследованным явлением по отношению к сфере производства. Однако, в непроизводственной сфере учет эффекта затруднен, хотя эффективность любой социально-значимой деятельности (оборона, медицина, просвещение, наука и т.д.) является очевидной для развития страны. Без такой непроизводственной деятельности невозможно развитие производства, общества и государства. Следует отметить, что при весьма распространенном понимании категории эффективности определение эффекта в бюджетном процессе и в непроизводственной сфере вообще весьма размыто. Принцип эффективности и экономии при использовании бюджетных материальных ресурсов определен еще в принятой в 1977 году «Лимской декларации руководящих принципов контроля». В качестве принципа эффективности использования бюджетных средств он был закреплен в Бюджетном кодексе Российской Федерации. Положения Лимской декларация является основной доктриной по вопросам государственного контроля и государственного аудита, которая выступает основным документом для высших органов финансового контроля ИНТОСАИ государств, независимо от региона, степень их развития и интеграции в систему управления или на пути их внутренней организации. Счётная палата России стала членом ИНТОСАИ в 1995 году. Суть этих моментов выступает положение о проведении независимой (внешней) ревизии в государственном секторе. Любой аудит не может осуществлять ревизию бюджетных организаций, если он не соответствует доктрине «Лимской декларации руководящих принципов контроля» и базовому стандарту в соответствии с верховенством закона. Принцип эффективности использования бюджетных средств предполагает конкретизацию ряда моментов, например, уточнение понятие эффективности управления бюджетными организациями, разграничение бюджетной и коммерческой (рыночной) их деятельности, нет четкого понятий категорий эффективности норм и эффективности их реализации, отсутствует системное представление о качестве услуг бюджетных организаций, представляемых за счет бюджетного финансирования. Критерий эффективности бюджетных средств предполагает наличия ряда вариантов их использования (например, закуп- 
ка одного и того же вида медицинского оборудования в разных регионах страны при сравнении цен и соответствующих технико-экономических показателей). При этом эффективность использования бюджетных средств может носить и отрицательное значение по отношению к некому среднему варианту. Конкретное понятие этой категорий эффективности весьма важно, т.е. в юридическом процессе необходимо опираться на определенные институциональные нормы. С этих позиций финансовый контроль как за расходованием госбюджета, так собственно за деятельностью бюджетных организаций в целом должен сосредотачиваться на эффективности управления бюджетной системой и здесь аудит играет существенную роль. Определяя эффективность управления бюджетной системой как социально-ценное свойство можно представить её как формулу, где знаменателем выступают затрат бюджетных средств на достижение поставленных целей, а те или иные достигнутые цели, полученные результатов финансирования в количественном отношении можно рассматривать как некий интегрированный числитель. Иначе, эффективным можно считать такое управление бюджетным процессом, которое позволяет достигнуть поставленные обществом цели в совокупности, своевременно и с наименьшими издержками способствовать установлению наиболее оптимального соотношения между различными видами деятельности [4]. О.И. Короткова отмечает, что «принцип эффективности управления заключается в достижении цели управления (определенного качественного результата деятельности или состояния объекта управления) ценой максимальной экономии ресурсов». [5] Определяя на законодательном уровне рост эффективности как цель управления, мы подчеркиваем, что достижение этой цели предполагает максимальную экономию бюджетных ресурсов на всех уровнях хозяйствования. Этим мы не снимаем задачу обоснованности самой цели бюджетного финансирования, т.е. выбора продукции и услуг, которые необходимы для реализации поставленной социально-экономической цели. Речь идет об учете результата (эффекта) и ресурсов бюджетного финансирования, что и позволяет обоснованно подойти к понятию эффективности бюджетного финансирования. Факт существование в этом процессе непроизводственной сферы как объекта экономических и правовых отношений не меняет общую логику определения эффективности процесса бюджетного финансирования. В соответствии с Бюджетным посланием Президента РФ одной из задач бюджетной политики на средне- и долгосрочную перспективу был вопрос координации долгосрочного стратегического и бюджетного планирования. Масштабы сферы бюджетного финансирования таковы, что здесь без разработки государственных долгосрочных планов экономического развития решить проблему эффективности бюджетного финансирования как на федеральном, так и на региональном и муниципальном уровнях невозможно. В этом аспекте уже сейчас важное значение имеют Концепция долгосрочного социально-экономического развития Российской Федерации, разработанная на период до 2020 г., а также Бюджетная стратегия до 2023 года [7]. Однако в Концепции 2020 нет специального раздела по вопросам финансового обеспечения достижения намеченных стратегических целей и решения поставленных задач. Бюджетная стратегия безусловно базируется на долгосрочных стратегиях и должна учитывать оценку финансовых возможностей для увеличения расходов по приоритетным направлениям на региональном или муниципальном уровне. Финансирование обороны, здравоохранения, образования и науки, развития инфраструктуры и т д. становиться главным мотивом государственной деятельности в РФ. В аспекте стратегии развития государства представляло бы целесообразно создание института в виде государственной плановой комиссии при Правительстве РФ, которая бы занималась составлением планов стратегии развития нашей страны, объединяя на основе принципов цифровой экономики общеэкономические, отраслевые и финансовые структуры государственного управления в РФ. Это стало бы импульсом к реформированию системы государственного и муниципального управления бюджетной системы не только с позиций среднесрочного планирования, но и с учетом стратегического прогнозирования, а значит на этой основе и обеспечило бы переход к стратегическому программно-целевому бюджетированию. Необходимо учитывать, что во многих странах программный подход стал важным элементом хозяйственного механизма. Достижение более высокого уровня оптимизации бюджетного процесса, учет социально-экономического эффекта финансовых затрат государства требует и более совершенных форм 
государственного контроля, основанного на новейших информационных технологиях в рамках модели цифровой экономики, с помощью которых можно было бы осуществлять прогнозирование относительно уровня достижения запланированных социально экономических результатов [9]. Кардинальные изменения в подходе к управлению эффективностью бюджетного финансирования с учетом развития планирования и прогнозирования в нашей стране и перехода к цифровой экономике, равно как и институционализация этих процессов на основе совершенствования законодательной и нормативной базы, более актуальным делает вопрос об аудите использования бюджетных средств и бюджетных организаций. Это обусловлено рядом моментов: самостоятельностью бюджетов разных уровней от федерального до муниципального, изменение цели бюджетирования, сложностью межбюджетных отношений, расширение прав и повышение правовой ответственности субъектов бюджетного процесса, переход к программно-целевому методу бюджетного планирования и др. Рост государственного финансирования социально-экономической сферы в РФ, расширение межбюджетных отношений предъявляет новые требования к контролю за эффективностью бюджетных расходов. Это способствует существенному повышению роля аудита в современном хозяйственном механизме, который институционально становиться инструментом общественного контроля за уровнем социально-экономической эффективности бюджетной деятельности государства. Последнее способствует созданию необходимые условия для предотвращения кризисных явлений, прежде всего, в денежно-кредитной и бюджетно-налоговой сферах [10]. Несмотря на важность аудита эффективности бюджетного финансирования можно констатировать, эта концепция ещё не нашла достаточного полного правового обеспечения, требуется уточнение понятий аудит эффективности бюджетного финансирования, аудит бюджетных и некоммерческих организаций. Часть исследователей склонна относить аудит эффективности к форме, виду или типу государственного финансового контроля [11], другие считают, что это конкретное контрольное мероприятие [12] или метод контроля [13], третьи склонны отграничивать государственный аудит эффективности от государственного финансового контроля [14], отдельные авторы включают аудит эффективности в число функций государственного финансового контроля. Проблемы, связанные с различным пониманием аудита управления эффективности бюджетного финансирования, усложняют работу уполномоченных органов контроля (включая и правоохранительные структуры) за использованием бюджетных средств. В настоящее время требуется серьезное обоснование функций аудита управления бюджетным финансированием, его институциональной позиции в системе хозяйственных отношений.

На основе действующих законов и нормативных актов оценка доходных и расходных статей в проектах федерального бюджета и бюджетов федеральных внебюджетных фондов государственным финансовым контролем осуществляется с позиций проверки законности предполагаемых финансовых решений уполномоченных органов. По сути это можно рассматривать как традиционным видом финансового контроля, который не может быть предметом аудита эффективности. В РФ аудиторные оценки эффективности бюджетного финансирования осуществляется Счетной палатой России и счетными палатами в субъектах РФ. Так, в 2017 году Счетной палатой России было проведено более 100 аудитов эффективности использования бюджетных средств. Основными направлениями контроля в рамках данного направления являлась проверка эффективности принимаемых Правительством Российской Федерации и Центральным банком Российской Федерации мер по повышению устойчивости финансовой системы Российской Федерации и развитию реального сектора экономики. Счетная палата осуществляла также оперативный контроль и мониторинг эффективности мер государственной поддержки, направленных на стабилизацию финансовой системы и повышение устойчивости российской экономики. Счетной палатой по итогам прошедшего периода 2017 г. было выявлено более 6,5 тыс. нарушений на общую сумму 1,9 трлн. руб. В результате контрольной деятельности Счетной палаты в 2017 г. в бюджетную систему Российской Федерации было возвращено 18,8 млрд. руб. (в 2016 г. сумма возврата составила 8,8 млрд. руб.). При этом по большинству выявленных нарушений возврат средств в бюджетную систему в принципе невозможен. Инспекторами Счетной палаты в 2017 г. было возбуждено 389 дел об административных правонаруше- 
ниях, из числа которых к настоящему моменту судами рассмотрено 267 дел. На основании постановлений судов к административной ответственности привлечено 119 должностных лиц и 11 юридических лиц, которым назначены административные наказания в виде административных штрафов на общую сумму 23,4 млн. руб. (в 2016 г. привлечено к административной ответственности 110 должностных лиц, судами назначено административных штрафов на сумму 33,6 млн. руб.). По предварительным итогам
2017 г. Счетной палатой в правоохранительные органы направлено 124 материала контрольной деятельности (Генеральная прокуратура - 84 материала, ФСБ - 21, Следственный комитет 13, МВД - 6) [15]. Официальные отчеты Счетной палаты представляются в Совет Федерации и Государственную Думу Федерального Собрания, что соответственно оказывает влияние на законотворческую и законодательную деятельность Федерального Собрания России как самостоятельной ветви власти в нашей стране.

\section{Библиографический список}

1. URL: www.worldbaiik.org/ governance/ wpgovernance.

2. Концепция административной реформы в Российской Федерации: распоряжение Правительства Российской Федерации от 25 октября 2005 г. № 1789-р.

3. Ожегов С.И., Шведова Н.Ю. Толковый словарь русского языка. Москва. 1997. С. 78.

4. Жинкин С.А. Некоторые методологические аспекты исследования эффективности норм права // Юридический мир. 2017. № 4. С. 20.

5. Короткова О.И. Усиление государственного влияния на открытые акционерные общества как административно-правовая функция государственного управления // Законодательство и экономика. 2011. № 3. С. 23.

6. Рябухин С., Климантов С. Аудит эффективности государственного сектора экономики: Курс лекций. 2-е изд., доп. Москва. 2016. С. 71.

7. Климанов В.В. Стратегическое и бюджетное планирование: проблемы координации // Губернский деловой журнал. 2015. № 10.

8. Нестеренко Т.Г. Бюджет-2017: выбор целей // Российская газета. 2006. 24 ноября. Барыкин Е.А. Аудит эффективности в механизме государственного финансового контроля //Реформы и право. 2017. № 3. - С. 32.

9. Азжеуров В. Аудит эффективности использования бюджетных средств в интересах стратегии социально-экономического развития Российской Федерации // Бюджетные учреждения: ревизии и проверки финансово-хозяйственной деятельности. 2017.-№ 6.

10. Рябухин С.Н. Аудит эффективности государственных расходов в современной практике финансового контроля // Финансы. 2013. № 4. С. 55.

11. Мешалкина Р.Е. Аудит эффективности - объективная необходимость // Финансы. 2015. № 2. С. 66.

12. Рик T.А., Титов В.В. Государственный аудит как вид финансового контроля в правовой системе Российской Федерации // Право и экономика. 2015. № 9.

13. Рябухин С.Н. Аудит эффективности использования государственных ресурсов. Москва. 2014.

14. Барыкин E.А. Аудит эффективности в механизме государственного финансового контроля //Реформы и право. 2008. № 3. С. 54.

15. Интернет сайт Счетной палаты РФ // http://www.ach.gov.ru

16. Горшков М.К. Российское общество как оно есть: (опыт социологической диагностики). Москва. 2015. С. 131. 